\title{
Implementation Multi Representation and Oral Communication Skills in Department of Physics Education on Elementary Physics II
}

\author{
Intan Kusumawati ${ }^{1^{*}}$, Putut Marwoto ${ }^{2}$ and Suharto Linuwih $^{2}$ \\ 1. Department of Physics Education, High School in Teaching and Education (STKIP) Singkawang, Singkawang 79251, West Borneo \\ 2. Department of Physics Education, State University of Semarang (Unnes), Semarang 50233, Central Java
}

\begin{abstract}
The ability of multi representation has been widely studied, but there has been no implementation through a model of learning. This study aimed to determine the ability of the students multi representation, relationships of multi representation capabilities and oral communication skills, as well as the application of the relations between the two capabilities through learning model Presentatif Based on Multi representation (PBM) in solving optical geometric (Elementary Physics II). A concurrent mixed method was used with qualitative-quantitative methods. Means of collecting data in the form of the pre-test and post-test are essay form, observation sheets of oral communication skills, and assessment of learning by observation sheet PBM learning models, they all have a high degree of validity category, which is 3.91, 4.22, 4.13, and 3.88, respectively. Test reliability with Alpha Cronbach technique, the reliability coefficient is 0.494 . The students are in department of Physics Education Unnes as a research subject. Sequence multi representation tendency of students from high to low in sequence, representation of M, D, G, V; whereas the order of accuracy, the group representation V, D, G, M. Relationship of multi representation ability and oral communication skills are comparable/proportional. Implementation of conjunction can generate grounded theory. This study should be applied to the physics of matter, or any other university for comparison.
\end{abstract}

Key words: Elementary physics II, implementation, oral communication, multi representation.

\section{Introduction}

Multi representation research has been widely applied [1] because it can simplify the analysis of issues related to the concepts of physics [2], but there is no implementation about it. Representation of mathematics, most commonly used to problems solving found of physics [3]. In fact, the students who can represent the problem solving more than one representation (multi representations) tend to have a higher understanding of the concepts and are more skilled than students who only uses a representation only [4, 5]. Learning systems tend to approach mathematics, so that students are stuck in the habit of mathematics without understanding the physical

\footnotetext{
Corresponding author: Intan Kusumawati, master of education, research field: physics. E-mail: Intankusumawati10@gmail.com.
}

meaning of a concept. Thus, there should be an analysis of the ability of multi representation of students, and strategies for multi representation tendency of students to be evenly distributed across all forms of representation.

The ability of a good multi representation affect learning outcomes [3], as well as the oral communication skills [6]. Oral communication skills play an important role in achieving the learning objectives [7]. In addition, multiple intelligences also has contributed to these capabilities. Thus, the ability of multi representation and oral communication skills has been both associated with multiple intelligences and the comprehension of concept. If both of these capabilities have been associated with the concept of multiple intelligences and the comprehension of concept, this capability has the second definite 
relationship. However, so far no studies have shown a link between the ability of multi representation and oral communication skills (proportional) in geometrical optics problem solving, thus becoming one of the goals of this research.

Application of the relationship between these capabilities can be realized through the establishment of a new model of learning, it is learning model PBM (Presentatif Based on Multi representation). PBM learning model is designed based on the results of the pre-research, it was found that it is still not optimal to value student's Unnes in Elementary Physics II courses; there are students who have difficulties in geometrical optics material in the course Physics II; students tend to use mathematical representations in problem solving because it has been accustomed to in high school.

These findings are expected to help faculty to identify deeply about the ability of multi representation and oral communication skills of students, so that students can easily provide learning to achieve the desired learning objectives. In addition, they are expected to add insight and knowledge, and can be used as reference material for further research.

\section{Methods}

The methods used in this study are concurrent mixed methods with qualitative-quantitative. More dominant qualitative methods are used in this study compared with quantitative methods. This study examines in depth about the description or picture of the subject of research with qualitative standpoint (the researcher as research instrument), and form a grounded theory in the formulation of research problems. It uses the research instrument in the form of observation papers, human instrument, and test item. The instrument test item consists of five test questions about the essay form, reliability was tested using Cronbach Alpha technique. Found values are reliability categorized, that is equal to 0.494. Means of collecting data are in the form of the initial test and the final form of essays, observation sheets of oral communication skills, and assessment of learning by observation sheet PBM-learning models with a high degree of validity category, 3.91, 4.22, 4.13, 3.88, respectively.

This study originated from the decision about the value of data by providing an early test of the optics geometry in Elementary Physics II course on physics education students Unnes. Once the data is analyzed, some students were randomly selected in each group representations $(\mathrm{V}, \mathrm{D}, \mathrm{G}, \mathrm{M})$ in the category (high, medium, low) to present the results of the answer, and his performance was rated by peers (peer assessment). Thus, the relationship is known of its multi representation ability and oral communication skill (proportional or inversely), subsequently applied through the learning model PBM. The effect of the application of the PBM model of learning is known from the results of the students' answers, which were randomly selected to be given about the challenge.

The learning model gives enough flexibility to enable teachers to use their own creativity through all the expertise and knowledge, to include three criteria: objectives, phases, and foundations [8]. Thus, learning models can be designed according to the needs and desired learning objectives.

The learning model PBM syntax is as follows.

(1) The division of the group representation of verbal (V), picture/diagram (D), mathematics (M), and the graph $(G)$ is based on the acquisition of the answers to given problem.

(2) Each group was instructed to make a matter of its dominant representation and its corresponding solution. By default, the group representation is transformed into a representation of the group V', D', M', and G'.

(3) Each of the two groups combined representation for the transfer of information through oral communication (eg., group representations $\mathrm{V}^{\prime}$ combined with representations of the group D', be a group representation $\mathrm{V}^{\prime} \mathrm{D}$ ', and group representation $\mathrm{M}^{\prime}$ combined with representations of the group $\mathrm{G}^{\prime}$, be a group representation $\left.M^{\prime} G^{\prime}\right)$.

(4) All group representations (eg. group 
representation V'D' and M'G') coupled to the transfer of information through oral communication, thus forming multi representation group that had been given treatment (group multi representation V'D'M'G').

(5) Selected one person as a participant and a person as a challenger of different representations by randomly selecting, that formed the earliest group of representations (group representation V, D, M, G).

(6) Participants may choose one of the concepts that are mastered, read about the challenges and challengers to challenge the participants to finish it in the form as desired by the representation challenger.

(7) If having difficulties, participants may request assistance from one group member to pull lots representation that reads his name.

(8) If the participants were selected, and friends who helped are failed in explaining the group, and it would be disqualified and punished.

(9) If the participant successfully selected, then the prize (reward) would be given to him or her.

Based on the design of the PBM model of learning syntax, the implementation of the learning model PBM is formed as shown in Fig. 1.

\section{Results and Discussion}

This study found that there are differences between the findings and previous researches, students not only tend to use the representation of $\mathrm{M}[3,4]$, but also the representation of $\mathrm{D}$. The representation of $\mathrm{M}$ is only one point ahead than $\mathrm{D}$. The order of priority of the trend of using multi representations from high to low, the representation of $M, D, G, V$. This trend is influenced by the multiple intelligences, habit, and environment of study; while the multi representation accuracy affected are the comprehension of concept, embedded knowledge, and exercise. The order of priority from high to low, the representation of V, D, G, M. Students group representation $\mathrm{V}$ higher than other representations because the majority of students found hobbies are reading, so that students more easily understand the concepts and ideas poured in the form of a sentence. Graph multiple representation capabilities are shown in Fig. 2.

Based on the results of the data, discovering that the relationship between the ability of multi representations (KM) and oral communication skills (KK) is proportional, KM high $\mathrm{KK}$ medium, KK medium KM medium, and KM low KK low. Student who's initially had low oral communication skills. Apparently after PBM applied learning models, all students were selected to be participants, able to answer the challenge question correctly and can communicate well verbally to peers. Students are able to solve problems in the representation of different forms of representation groups initially. All students experienced significant changes in value (increase in value) between post-test and pre-test. In addition, all students have a positive appreciation of the learning

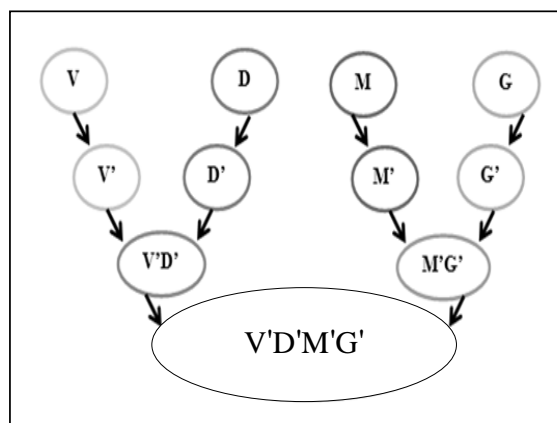

(a)



(b)

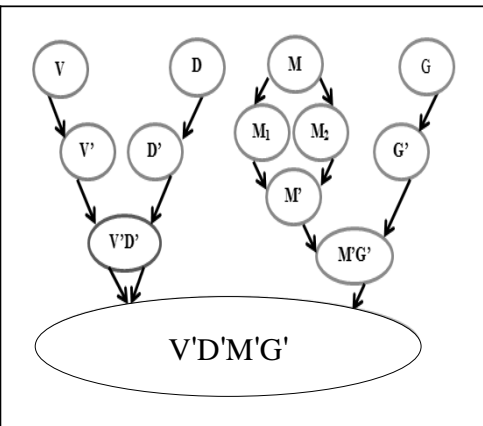

(c)

Fig. 1 Shape learning implementation model PBM. (a) PBM Model I, if the number of participants on each bit of the representation and the numbers are almost equal; (b) PBM Model II, if the number of participants on each lot and the number is almost equal representation; (c) PBM Model III, the number of participants in one representation is much more than other representations. 


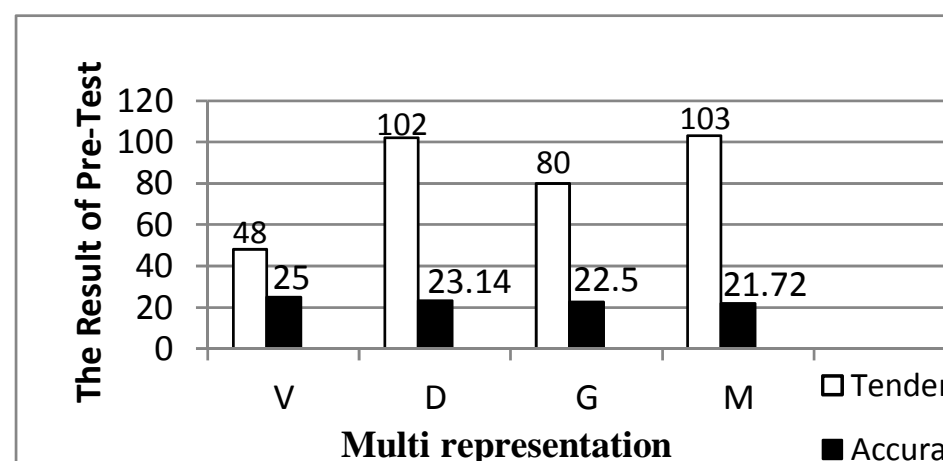

Fig. 2 The multi representation capability of students.

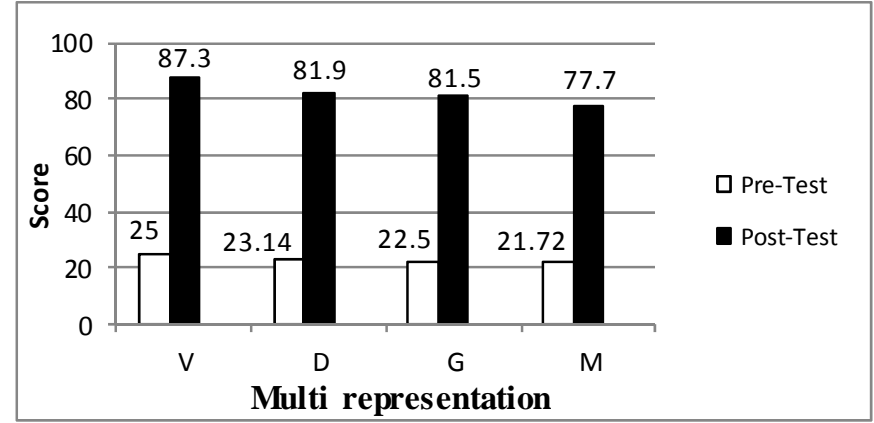

Fig. 3 Comparison of pre-test and post-test scores.

Table 1 The result of pre-test and post-test.

\begin{tabular}{lll}
\hline Representation groups & Pre-test & Post-test \\
\hline V & 25.0 & 87.3 \\
D & 23.1 & 81.9 \\
G & 22.5 & 81.5 \\
M & 21.7 & 77.7 \\
\hline
\end{tabular}

model viewed from a sheet of observer feasibility of study model PBM. The results of the acquisition of pre-test and post-test in terms of a group multi representation are shown in Table 1 , and Fig. 3.

\section{Conclusions and Recommendations}

Students tend to use the representation of $M$ and D problem solving. The order of priority of the trend of using multiple representations is from high to low, the representation of $M, D, G, V$, while the accuracy is dominated by the use of multi representation of the representation $\mathrm{V}$. Sequence the priority from high to low is the representation of $\mathrm{V}, \mathrm{D}, \mathrm{G}, \mathrm{M}$. The relationship of multi representation ability and oral communication skills of students in problem solving geometric optics is proportional. Application of the relationship of the multi representation ability and oral communication skills through learning model PBM in geometric optics problem solving can improve the understanding of concepts, ability to multi representation, and oral communication skills. This suggests that the learning model is a form of implementation of the PBM relationship multi representation ability and oral communication skills, which can be used as an alternative learning model in learning activities.

\section{Acknowledgements}

Thanks to STKIP Singkawang-West Borneo on research grants awarded; and Department of Physics Education S1, Semarang State University Unnes, it has now been granted permission for research.

\section{References}

[1] Mayer, R. E. 2003. "The Promise of Multimedia Learning: Using The Same Instructional Design Methods Accros Different Media, Learning and Instruction.” Journal Learning and Instruction 13 (1): 125-139.

[2] Zacharia, Z. dan Anderson, O. R. 2003. "The Effect of An 

Department of Physics Education on Elementary Physics II

Interactive Computer-Based Simulation Prior to Performing A Labolatory Inquiry Based Experiment on Students' Conceptual Understanding of Physics.” Americans Journal of Physics 71 (6): 618-629.

[3] Meltzer, D. E. 2005. "Relation Between Students' Problem-Solving Performance and Representational Format.” American Journal of Physics 73 (5): 463-478 .

[4] Kohl, P. B., David, R., and Noah, D. F. 2007. "Strongly and Weakly Directed Approach to Teaching Multiple Representation Use in Physics.” Physical Review Special Topics- Physics Education Research 3: 10-108.

[5] Prain, V. dan Waldrip, B. G. 2008. “An Exploratory Study of Teachers' Perspectives about Using Multi-modal
Representations of Concepts to Enhance Science Learning." Canadian Journal of Science, Mathematics and Technology Education 8 (1): 5-24.

[6] Rohaeni, M. A. 2013. "The Emergence of A Tragic Hero: A Narrative Analysis of Chinua Achebe's Things Fall Apart.” thesis, UPI University.

[7] Novita, N. 2010. "Pentingnya Komunikasi Verbal Dalam Proses Pembelajaran: Kajian Perspektif Komunikasi Efektif pada Pembelajaran.” Jurnal Manajemen Informatika 2 (1): 102.

[8] Eggen, P. and Don, K. 1996. Strategie and Models for Teachers: Teaching Content and Thinking Skills, Sixth Edition. Boston. U.S. 